\title{
Anaplastic ependymoma
}

INSERM

\section{Source}

INSERM. (1999). Orphanet: an online rare disease and orphan drug data base. Anaplastic ependymoma. ORPHA:251646

Anaplastic ependymoma is a rare, malignant type of ependymoma (see this term) that most often arises in the supratentorial region of the brain of children and young adults and that manifests with variable symptoms including headaches, nausea, vision impairment, memory loss and difficulty walking. 